\title{
A Non-parametric Approach to estimate the technical efficiency of paddy farmers in southern region of Tamil Nadu, India
}

\author{
S.Kannaki ${ }^{*}$, L. Mary Louis ${ }^{2}$ \\ ${ }^{1 *}$ Dept. of Mathematics, Avinashilingam University, Coimbatore, India \\ ${ }^{2}$ Dept. of Mathematics, Faculty of Engineering, Avinashilingam University, Coimbatore, India \\ *Corresponding Author: kanmanivijay7@gmail.com
}

Available online at: www.isroset.org

Received 16/Dec/2017, Revised 30/Dec/2017, Accepted 22/Jan/2018, Online 28/Feb/2018

\begin{abstract}
The purpose of the study is to analyze the technical efficiency level of paddy farmers in Thiruvarur District of Tamil Nadu, India. A Non-Parametric approach of Data Envelopment Analysis method (DEA) was employed to measure the technical efficiency under Variable returns to Scale (VRS) with output oriented assumption. A primary data for the year 201516 was collected from 300 farmers of Thiruvarur District in Tamil Nadu. The findings shows that the average technical efficiency was $64 \%$ which implied that $64 \%$ of the farmer in the study area had realized their technical abilities. The estimated technical efficiency range varied from $14 \%$ to $100 \%$ and also 13 farmers were technically efficient. Average potential to increase the paddy production was $83 \%$ by following the best-practices of efficient farms. Tobit regression model was applied in this study to examine the socio-economic factors influences technical efficiency. The result shows that age of the farmer, sex and marital status had positive relationship to the technical efficiency.
\end{abstract}

Keywords- Technical efficiency, Data Envelopment Analysis, paddy production, Tobit regression analysis.

\section{INTRODUCTION}

Efficient management of resources in any production system relates the producing outputs with maximum economic returns. A mathematical model that relate inputs with output is used by researchers to gain insight on the responses of output due to changes in inputs, so that the most influencing input variables are managed for maximum yield. The measurement of firm specific technical efficiency is based upon deviations of observed output from the best production or efficient production frontier. Farrell (1957) established the technical efficiency concept based on the relationship between set of inputs and outputs. Parametric method (Stochastic Frontier Analysis) and Non-Parametric method (Data Envelopment Analysis) are the two commonly used methods to measure the technical efficiency. DEA (Data Envelopment Analysis), which is the non-parametric method used in this study. It is a linear programming approach, which is used to relate the efficiencies and also helps to differentiate efficient farmers from inefficient farmers. DEA was introduced by Charnes et al (1978) with the assumption of Constant returns to scale (CRS).This model is known as CCR or CRS model. DEA model is suitable only when the farm is operating at an optimal scale. The factors like imperfect competition, financial constraints, etc. will not allow the farm to operate optimally. Banker et al. (1984) introduced variable returns to scale (VRS) model, and this model is known as BCC or VRS model which will overcome the above mentioned problems. The present study follows VRS method to estimate the technical efficiency of paddy farmers in Thiruvarur district which is in the southernmost tip of Tamil Nadu. Many researchers used DEA to measured efficiency in paddy production Juan Xiao and Dongmei Li (2011) analyzed the efficiency of paddy in china using BCC model of DEA method. The result showed that the tendencies of pure technical efficiency and scale efficiency are opposite and the pure technical efficiency has great impact on paddy production. Umanath \& David Rajasekar (2013) examined the efficiency level of paddy farms in Madurai district of Tamil Nadu state in India. The input oriented Data Envelopment Analysis (DEA) was employed to estimate the technical efficiency. Their study indicated that all the farm inputs were used excessively by the sample farms; the excessive use of nitrogen and women labor was found in the case of fifty percent of the sample farms. Nargisand Lee (2013) estimated the technical, allocative, economic, and scale efficiency using field-level survey data from a sample of 199 Boro rice farmers in north-central part of Bangladesh. Taraka et al (2010) investigated the technical efficiency of rice farms in Central Thailand. They applied both CRS and VRS models in DEA. Tobit regression model also applied to identify the factors affecting technical efficiency. Recently, Parichatnon et al (2017) investigated the technical efficiency of rice production in four regions of 
Thailand using data envelopment analysis (DEA) model. Their results showed that the technical efficiency in their production and environmental factors have a significance influence on the production efficiency. In this study, the technical efficiency by using VRS -DEA method is estimated and also Tobit regression model is used for the determination of inefficiency factor.

The present study is organized as follows, Section I contains the introduction of Data Envelopment Analysis method (DEA), Section II contain model specification and collection of data for the present study, Section III describes results and discussion of technical efficiency by VRS-DEA method and identifying the factors influencing the efficiency by Tobit regression method., Section IV contain conclusion and recommendation for the improvement of technical efficiency of the farmer.

\section{MODEL SPECIFICATION AND DATA COLLECTION}

\section{A. Model specification:}

In the present study, Variable Returns to Scale (VRS) -DEA model was used to estimate the technical efficiency.DEA is a linear programming method which is used to construct the efficient frontier with the best performing observations of the sample used. By the assumption of Variable returns to scale, the following output oriented linear programming method was used to find the technical efficiency of paddy farms.

$\operatorname{Max}_{\theta, \lambda} \theta$

Subject to $-\mathrm{y}+\mathrm{Y} \lambda \geq 0$

$\theta \mathrm{x}_{\mathrm{i}}-\mathrm{X} \lambda \geq 0$

$\lambda \geq 0$

$\mathrm{N}_{1} \lambda=1$

where, $y$ is a $\mathrm{m} \times 1$ vector matrix of output for $\mathrm{i}^{\text {th }}$ farm,(i.e.) $y=\left[\begin{array}{l}y_{1} \\ y_{2} \\ \vdots \\ y_{m}\end{array}\right]$

$\mathrm{x}_{\mathrm{i}}$ is a $\mathrm{k} \times 1$ vector matrix of inputs for $\mathrm{i}^{\text {th }}$ farm, (i.e.) $x_{i}=\left[\begin{array}{l}x_{1} \\ x_{2} \\ \vdots \\ x_{k}\end{array}\right]$
$\mathrm{Y}$ is a $\mathrm{n} \times \mathrm{m}$ output matrix for ' $\mathrm{n}$ ' number of farms, (i.e.) $x_{i}=\left[\begin{array}{lll}Y_{11} & Y_{12} \ldots Y_{1 m} \\ Y_{21} & Y_{22} & \ldots Y_{2 m} \\ \vdots & \\ Y_{n 1} & Y_{2 n} \ldots Y_{n m}\end{array}\right]$

$\mathrm{X}$ is a $\mathrm{n} \times \mathrm{k}$ input matrix for ' $\mathrm{n}$ ' number of farms, (i.e.) $X=\left[\begin{array}{lll}X_{11} & X_{12} \ldots X_{1 k} \\ X_{21} & X_{22} \ldots X_{2 k} \\ \vdots & \\ X_{n 1} & X_{2 n} \ldots X_{n k}\end{array}\right]$

$\mathrm{N}_{1}$ is a $\mathrm{n} \times 1$ vector matrix, (i.e.) $N_{1}=\left[\begin{array}{l}R_{1} \\ R_{2} \\ \vdots \\ R_{n}\end{array}\right]$

$\theta$ is an efficiency score, it is a scalar whose value would be the efficiency measure for each ' $i$ ' farm and it ranges between 0 and 1 . If $\theta=1$, then the farm would be efficient; otherwise, the farm would be below the efficient level, and $\lambda$ is $\mathrm{n} \times 1$ vector of matrix which provides the optimum solution. The $\lambda$ values are used as weights in the linear combination of other efficient farms for an inefficient farm.

\section{B. Data collection:}

The data for this study was collected from Thiruvarur district of Tamil Nadu. There are 10 blocks in Thiruvarur district. Among this 10 blocks, three blocks namely Thiruvarur, Thiruthuraipoondi, Kottur were selected for the study. From this blocks, 50 villages were randomly selected and from this 50 villages 300 farmers were randomly selected. So, totally 300 data with seven inputs such as seed, human labour, machine labor, farm yard manure and the chemical fertilizers nitrogen, phosphorus, potash was collected during the year 2015-16(Samba season).

\section{RESUlTS AND DISCUSSION}

Table 1 Summary statistics of technical efficiency

\begin{tabular}{|l|l|}
\hline $\begin{array}{l}\text { Technical } \\
\text { efficiency }\end{array}$ & $\begin{array}{l}\text { Percentage } \\
(\%)\end{array}$ \\
\hline Mean & 64 \\
\hline Median & 60 \\
\hline Std.Dev & 17 \\
\hline Minimum & 14 \\
\hline Maximum & 100 \\
\hline
\end{tabular}


The summary statistics of technical efficiency is presented in the Table 1.The result showed that the technical efficiency ranges from 14 percent to 100 percent and the mean technical efficiency is 64 percent. This result showed that 64 per cent of the farmers had realized the technical abilities in the study area and the remaining 36 percent couldn't realize their abilities. It is also noted that the average potential to increase the technical efficiency of the farmer is 17 percent. [i.e.1(Mean Technical efficiency/Maximum Technical efficiency)] and the minimum efficiency farmer can reach the maximum level of efficiency by 86 per cent [i.e. $\{1$-(minimum Technical efficiency/Maximum Technical efficiency)\}, Hidayah, 2013].

\section{Chart A- Frequency distribution of technical efficiency under VRS assumption.}

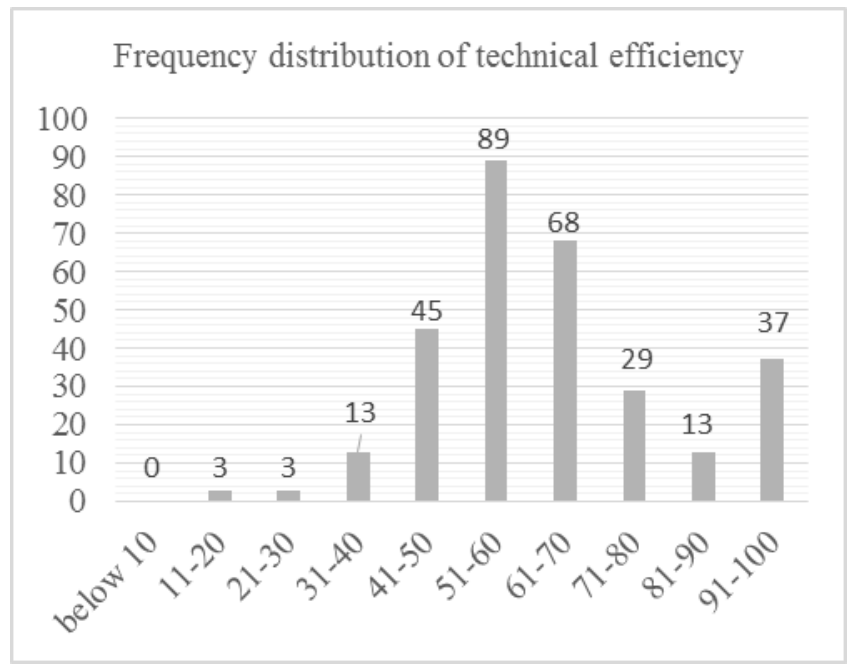

The frequency distribution of technical efficiency under VRS model is presented in the above chart A. It could be inferred from the chart that there is no firm which had technical efficiency frequency of less than 10 per cent. There are three farms within the frequency of 11-20 per cent and 21-30 per cent of technical efficiency. The result also shows that the frequency of technical efficiency 51-60 per cent has highest number of farms (89).Moreover, 13 farms had 100 per cent efficiency.

\section{A. Identification of the factors influencing efficiency}

Tobit regression model is used to identify the factors that influences the technical efficiency is the second step of analysis. Tobit model, which is a censored regression model, applicable where the dependent variable is constrained in some way. Here the dependent variable, technical efficiency is a censored variable with an upper limit of one (Lockheed et al., 1981), it is appropriate to use the Tobit model. The Tobit model is defined as follows.

$$
\begin{aligned}
& y_{i}= \begin{cases}y_{i}^{\#} & y_{i}^{\#}>0 \\
0 & y_{i}^{\#} \leq 0\end{cases} \\
& y_{i}^{\#}=\beta x_{i}+\delta_{i}, \delta_{i} \rightarrow N\left(0, \sigma^{2}\right)
\end{aligned}
$$

Where $y_{i}$ is the DEA efficiency score;

$y_{i}{ }^{\#}$ is the latent(unobservable) variable;

$\beta$ is the vector of unknown parameters which determines the relationship between the independent variables and the latent variable;

$x_{i}$ is the vector of explanatory variables;

The Tobit regression model used in this study is

$y_{i}^{\#}=\beta_{0}+\beta_{1} X_{1}+\beta_{2} X_{2}+\beta_{3} X_{3}+\beta_{4} X_{4}+\beta_{5} X_{5}+\beta_{6} X_{6}+\beta_{7} X_{7}+\delta_{i}$

Where $y_{i}^{\#}$ is the DEA technical efficiency -dependent variable.

$X_{1}=$ Age of the farmer (in Years),

$X_{2}=$ Experience of the farmer (in Years),

$X_{3}=$ Sex of the farmer (1=male, 0 otherwise),

$X_{4}=$ Education level of the farmer $(0=$ illiterate, $1=$ primary, 2= high school, 3=higher Secondary, 4=graduation), $X_{5}=$ Number of family members (in Numbers),

$X_{6}=$ Marital status (1=married, 0 otherwise),

$X_{7}=$ farmers who received loan $(1=$ received, 0 otherwise $)$

$\delta_{i}=$ error term.

Table 2 Estimated co- efficient of the Tobit regression model

\begin{tabular}{|l|c|c|c|}
\hline \multicolumn{1}{|c|}{ Variable } & Parameter & Coefficient & t-ratio \\
\hline Constant & $\beta_{0}$ & 18.0 & 1.6 \\
\hline $\begin{array}{l}\text { Age of the farmer (in } \\
\text { Years) }\end{array}$ & $\beta_{1}$ & $0.21^{* *}$ & 1.8 \\
\hline $\begin{array}{l}\text { Experience of the farmer } \\
\text { (in Years) }\end{array}$ & $\beta_{2}$ & -0.1 & -1.0 \\
\hline $\begin{array}{l}\text { Sex of the } \\
\text { farmer(1=male,0 } \\
\text { otherwise) }\end{array}$ & $\beta_{3}$ & $11.02^{*}$ & 3.4 \\
\hline $\begin{array}{l}\text { Education level of the } \\
\text { farmer } \\
\text { (0=illiterate, } 1=\text { primary,2= } \\
\text { high } \\
\text { school,3=highersecondary } \\
\text { 4=graduation) }\end{array}$ & $\beta_{4}$ & 0.2 & 0.2 \\
\hline $\begin{array}{l}\text { Number of family } \\
\text { members (in Numbers) }\end{array}$ & $\beta_{5}$ & 1.3 & 1.7 \\
\hline
\end{tabular}




\begin{tabular}{|l|c|c|c|}
\hline $\begin{array}{l}\text { Marital } \\
\text { status(1=married,0 } \\
\text { otherwise) }\end{array}$ & $\beta_{6}$ & $24.4 * *$ & 2.4 \\
\hline $\begin{array}{l}\text { Loan } \\
\text { received(1=received,0 } \\
\text { otherwise) }\end{array}$ & $\beta_{7}$ & -3.4 & -1.6 \\
\hline Log likelihood function & \multicolumn{2}{|c|}{20.96} \\
\hline
\end{tabular}

The estimated Tobit regression model is

$y_{i}^{\#}=18+0.21 X_{1}+(-0.1) X_{2}+11.02 X_{3}+0.2 X_{4}+1.3 X_{5}+24.4 X_{6}+(-3.4) X_{7}+\delta_{i}$

The results of Tobit model using STATA 12.1 software presented in Table 2.The estimation showed that the sex of the farmer is significantly influencing the technical efficiency of the farmers. This indicates that the male farmers in the research area has performed well compared to the female farmers. By increasing the male farmers by 1 per cent, the technical efficiency will increase by 11.02 per cent The result also revealed that age had significantly influencing at 5 $\%$ level, this indicates that old farmers are highly technically efficient than the younger ones, because of the fact that aged farmers were more experienced. Even they are aware about their innovative technologies, they are following the traditional paddy cultivation technologies. Marital status had significantly influencing the technical efficiency at 5\% level. This indicates that the married farmers are more efficient than the unmarried. Experience and farmers who received loan are negatively influencing the technical efficiency of the farmers Family members and education are positively influencing the technical efficiency of the farmers.

\section{IV.CONCLUSION}

The present study was used to estimate the technical efficiency by VRS-DEA method and also analyzed socioeconomic factors which influence the technical efficiency of the farmers by Tobit regression model in paddy production among the paddy farmers in Thiruvarur District of Tamil Nadu, India. The study showed that the mean technical efficiency was $64 \%$ and the efficiency ranges from $14 \%$ to 100\%. 13 farms had 100 per cent efficiency. This indicates that only $64 \%$ of the farmer in the study area had realized their technical abilities. By using available technology, the farmers can increase their paddy production by $36 \%$.Tobit regression analysis shows the influence of various socioeconomic variables in technical efficiency. The variables age, sex and marital status had increased the efficiency. The present study suggested that to bring in technically efficient paddy production in the study region, the government have to provide necessary education, training, extension to bring in social change among farmers and other essential support in the form of credit and also there is a need to create general awareness about the accessible knowledge, skills and techniques to improve farm productivity and quality of paddy so that the farmers could earn sustainable income.

\section{REFERENCES}

[1] R.D. Banker, A.Charnes, W.W. Cooper "Some Models for Estimating Technical and Scale Inefficiencies in Data Envelopment Analysis", Management Science, 30(9), pp.1078$1092,1984$.

[2] A.Charnes,W.W.Cooper,E.Rhodes. "Measuring the Efficiency of Decision Making Units", European Journal of Operational Research, No. 2, pp.429-444, 1978.

[3] M.J.Farrell. "The Measurement of Productive Efficiency," J. Roy. Statist. Soc. Ser. A, 120, 253-290, 1957.

[4] Ismatul Hidayah, Nuhfil Hanani, Ratya Anindita, Budi Setiawan. "Production and Cost Efficiency using Frontier Stochastic Approach, A case on Paddy farming system with Integrated Plant and Resource Management(IPRM) Approach In Buru District Maluku Province Indonesia",Journal of Economics and Sustainable Development,Vol.4,No.1,2013.

[5] Juan Xiao, Dongmei Li. "An Analysis on Technical Efficiency of Paddy Production in China", Asian Social Science, Vol. 7, No. 6, 2011.

[6] Kallika Taraka,Ismail Abd.Latif, Mad Nasir shamsudin. “A Non parametric Approach to evaluate Technical Efficiency of Rice farmers in Central Thailand", Chulalongkorn Journal of Economics, 22, pp.1-14, 2010.

[7] M. E. Lockheed,D. Jamison, and L. J. Lau. "Farmer education and farm efficiency", A survey.Econ. Develop. Cultural Change 29: pp.37-76, 1981.

[8]F.Nargis and S. H. Lee. "Efficiency analysis of Boro rice production in North central region of Bangaladesh", The journal of animal and plant sciences, 23(2), pp.527-533, 2013.

[9] Surakiat Parichatnon, Kamonthip Maichum, Ke-Chung Peng. "Evaluating Technical Efficiency of Rice Production by Using a Modified Three-Stage Data Envelopment Analysis Approach: A Case Study in Thailand", International Journal of Scientific \&Technology Research, Vol.6, Issue 01, 2017.

[10] M.Umanath. \& D. David Rajasekar. "Estimation of Technical, Scale and Economic Efficiency of Paddy Farms: A Data Envelopment Analysis Approach", Journal of Agricultural Science; Vol. 5, No. 8, 2013.

\section{AUTHORS PROFILE}

S.Kannaki received her B.Sc. in Mathematics from E.M.G.Yadhava Women's College affiliated to Madurai Kamaraj University, Madurai, Tamil Nadu, India in 2003.She is currently a Ph.D. research scholar in Avinashilingam University, Coimbatore, Tamil Nadu, India. Her research is in Stochastic Production Frontier Analysis that is the mathematical modelling which can be applied in various real world fields.

L.Mary Louis received her B.Sc. in Mathematics, from Holy Cross College affiliated to Madurai Kamaraj University, Madurai, Tamil Nadu,India. She also received the Ph.D. in Stochastic Frontier Analysis from Avinashilingam University, Coimbatore, Tamil Nadu, India. She is currently an Associate Professor\&Head, Avinashilingam Faculty of Engineering, Coimbatore, Tamil Nadu, India. Her research interests include Stochastic Modelling. 